\title{
Benchmarking, Standard Setting and Energy Conservation of Olefin Plants in Iran
}

\author{
S. Gowharifar, \\ Head of Petrochemical Industry, \\ Iranian Fuel Conservation Company, \\ Tehran, Iran., \\ Gowharifar@Ifco.ir \\ B. Sepehrian, \\ Caspian Energy Company. \\ Tehran, Iran., \\ Baharehsepehrian@yahoo.com
}

\author{
G. Nasiri, \\ Head of HSE Department NIPC Company. \\ Tehran, Iran., \\ Nasiri@nipc.ir
}

\author{
M.Momenifar, \\ Senior Expert of Planning, \\ IKCO Company, \\ Tehran, Iran., \\ m.momenifar@Ikco.com
}

Received: February 17, 2021 Revised: March 10, 2021. Accepted: March 13, 2021. Published: March 29, 2021.

\begin{abstract}
Olefin plants are one of the most energy intensive petrochemical plants in the world [1, 2]. In Iran more than $15 \%$ of petrochemical products are olefins and it will increase rapidly during next future, so improvement of energy efficiency in olefin plants is key element in NPC (Iranian National Petrochemical Company) plan for cost reduction and sustainable development. In this paper the energy consumption of existing olefin plants are compared with design condition and also world best technology. This comparison indicates the meaningful gap between operational and best condition. In this study the opportunities of energy saving in olefin plants are investigated using process integration tools and benchmarking. The result of this study indicates there is potential for energy consumption reduction up to $25 \%$ in Iranian olefin plants.
\end{abstract}

Keywords- Energy efficiency; Energy analysis; Best technology; Benchmarking; Olefin; Ethylene; Gap Analysis; Specific energy consumption.

\section{INTRODUCTION}

Energy efficiency significantly affects profit margins of a plant, while increased cost of fuel and power, and more stringent environmental regulations makes it more important. Experience shows that the ability to benchmark and monitor energy efficiency is essential for successful implementation of an energy efficiency improvement program $[3,4]$. Energy benchmarking is the process of quantifying and comparing the energy consumption of a process unit or whole refinery/petrochemical plant to some pre-selected standard and to the rest of the industry. A system is needed to enable calculating and expressing each processing unit's energy efficiency as a single number so that performances of different units can be compared.

"Process energy use" is defined as the sum of fuel, steam and electricity in primary terms that are used for reactions (converting feedstock into olefins) and all the subsequent processes (e.g. compression and separation). SEC ( specific energy consumption: total energy consumption per ton of product) is one of the measuring tools for energy efficiency in plants[5] but it is not an accurate parameter, because the sites processing a complex feed are expected to consume more energy compared to ones with a simpler feedstock. The SEC also does not assess the unit operation (i.e. furnace severity) where focus can be moved to one or more products. Therefore SEC is poor parameter to be used to allow a true comparison between sites and even between different operating periods on the same plant. On the other hand BT (Best Technology) methodology provides a very reliable energy benchmarking tool, which has several advantages over other systems as following:

- It sets energy targets in terms of best available technology, and not just by comparison with the industry.

- It compares process units with what can really be achieved not just by theoretical targets.

- It provides basis for the "Gap Analysis" whereby areas of inefficiency can be identified and their contribution quantified.

\section{Process BT Index $=\quad$ Actual Energy Consumption Sum of Individual process Allowances}

- BT has best technology configuration behind it - this can be used to point out differences in process configurations between the actual and the efficient unit .

\section{Methodology}

The SEC of all olefin production plants was calculated and compared with world best technology and detailed study for some selected plants has been done to calculate BT Index and gap analysis. The allowed energy use for Ethylene Plant depends very much on the yield of ethylene, expressed as weight percentage of ethylene of the feed to furnace. If ethylene yield on fresh feed increases from $25 \mathrm{wt} \%$ to $50 \mathrm{wt} \%$, the total BT energy consumption increases by about $40 \%$. This means that recovery of ethylene requires more energy than the recovery of other products $[6,7]$. BT implies attainable 
efficiency, without assuming any constraint on investment or payout. Energy loss represents the difference between the total energy input and total energy output. Thermodynamic theoretical energy requirement is the minimum energy input requirement for converting naphtha to end products. It is the difference between the total calorific value of products and the calorific value of naphtha at ambient temperatures. The former is larger than the latter because the overall naphtha-based steam cracking reactions are endothermic. In order to compare energy efficiencies across different processes, we believe process energy use for steam cracking (thermodynamic theoretical energy requirements and energy loss together) can be used as a basis for comparing energy efficiency in this article. The correlation is expressed in terms of total energy per ton of fresh feed.

The following steps were taken to achieve the goals of this study:

\section{Step 1: Data Collection}

Collect, reconcile and validate data: The required data for this step are feed \& products specification and flow rates, all the utility import/export and generation in plants and also the required data for efficiency evaluation of main energy consumers in plant. For detailed study and benchmarking of selected plants the additional data collected to find the BT index and allowance of energy consumption [8]. These additional data were energy parameters on process to process Exchangers- Utility Exchangers and Steam generation systems. Collected data validated and reconciled to define a representative energy balance for the processes. The data was then analyzed and interpreted using ProSteam software for rigorous steam, water, power and fuel balances. SuperTarget software was used to calculate heat integration level of the unit.

\section{Step 2: Site BT Benchmarking}

In this step, Benchmarking of selected plants were done using BT methodology to compare against worldwide industry performance [9]. SEC parameter was used for remaining plants to compare operational condition with words best technology and design situation [10].

The following assumptions have been used to calculate SEC and BT index:

- The meaning of import is utilities taken from outside the plant's battery limits

- The power imported has been converted to a primary energy source. The energy value of the power imported from the site has been calculated assuming that an external power station would be generating power at an efficiency of $35 \%$ equivalent to a fuel consumption of $10.3 \mathrm{GJ}$ per MWH of power.

- Steam imported has been converted to a primary energy source. The energy value of the steam imported has been calculated assuming an external generation efficiency of $92 \%$.
- Fuel consumption includes fuel imported and any off gas from the process that is routed to the furnaces for fuel.

- Steam internally generated and consumed has been accounted for as fuel consumed.

- Where fuel, steam or power is exported then an energy credit is applied. There is also a credit if there is a significant high temperature condensate return to outside of battery limits.

The auxiliary utilities - cooling water, nitrogen, plant air, instrument air, potable water and fire water - have been included using their equivalent primary energy forms as these tend to be insignificant energy consumers (in comparison to fuel, steam and power), normally in constant use and are often already included in the power import

Step 3: Gap Analysis:

The BT index allows for direct comparison of the processes as it assesses the performance of the plants against an achievable design, with parameters accounting for variations in operation such as yield.

Step 4: Approach to Achievable SEC

Achievable SEC for each plant was calculated using gap analysis and defining realistic and feasible energy saving projects. During project development numerous options for energy improvement were reviewed and assessed in terms of applicability and economical viability. The projects listed in the following categories.

- Non-investment projects, implementation and optimization (operational)

- Minor investment projects, design, implementation and optimization

- Investment projects, design, implementation and optimization (Major Investment, pay back $<3$ years)

- Investment projects, design, implementation and optimization (Major Investment, pay back $<5$ years)

\section{Step 5: Energy Improvement Program}

The realistic and feasible projects in each plant are classified using technical and economic criteria, which are ranked according to their cost and duration to provide a Roadmap for each process. This Roadmap includes an energy improvement program that can form the basis of future energy improvements on other petrochemical sites that have not been studied in detail.

Step 6: Specific Energy criteria for new plants

The key design factors influencing energy consumption on each of the olefin process were identified. Then the results of detailed study and energy conservation programs were used to define SEC criteria for new plants. 


\section{SELECTED PLANTS FOR STUDY}

Major olefin production plants in Iran are distributed in two specific zone named petrochemical special economic zone ( Mahshahr ) and pars special energy zone ( Assaluyeh ) which are located in south of Iran. These specific zones are near hydrocarbon resources (oil and gas) and also have good situation for foreign investment and export of products. Two olefin plants are operating out of these zones, but they will increase rapidly by transferring ethane from pars special energy zone to other cities. Following table shows the existing and under construction olefin plants.

The following picture shows the sharing of operating plants in the production of olefin.

Table 1- olefin plants in Iran

\begin{tabular}{|c|c|c|c|c|c|}
\hline & Location & Plant name & Feed & $\begin{array}{l}\text { Production } \\
\text { Capacity } \\
\text { (kTon/yr ) }\end{array}$ & $\begin{array}{l}\text { Production/ } \\
\text { Construction }\end{array}$ \\
\hline 1 & \multirow{3}{*}{ 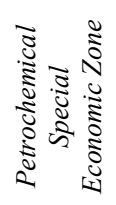 } & Bandar Imam & Naphtha/Ethane & 528 & Production \\
\hline 2 & & Marun & Ethane & 1300 & Production \\
\hline 3 & & Amir Kabir & Ethane & 678 & Production \\
\hline 4 & \multirow{4}{*}{ 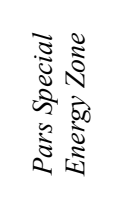 } & Arya Sasol & Ethane & 1000 & Production \\
\hline 5 & & Jam & Naphtha/Ethane & 1626 & Production \\
\hline 6 & & Morvarid & Ethane & 500 & Production \\
\hline 7 & & Kavyan & Ethane & 2000 & Construction \\
\hline 8 & \multirow{8}{*}{$\begin{array}{l}\stackrel{0}{0} \\
N \\
\bar{\Xi} \\
\tilde{0}\end{array}$} & Arak & Naphtha/Ethane & 434 & Production \\
\hline 9 & & Tabriz & Naphtha/Ethane & 192 & Production \\
\hline 10 & & Ilam & Ethane & 582 & Construction \\
\hline 11 & & Gachsaran & Ethane & 1000 & Construction \\
\hline 12 & & Firouzabad & Ethane & 1000 & Construction \\
\hline 13 & & Genaveh & Ethane & 500 & Construction \\
\hline 14 & & Dehloran & Ethane & 698 & Construction \\
\hline 15 & & Bushehr & Ethane & 1000 & Construction \\
\hline
\end{tabular}

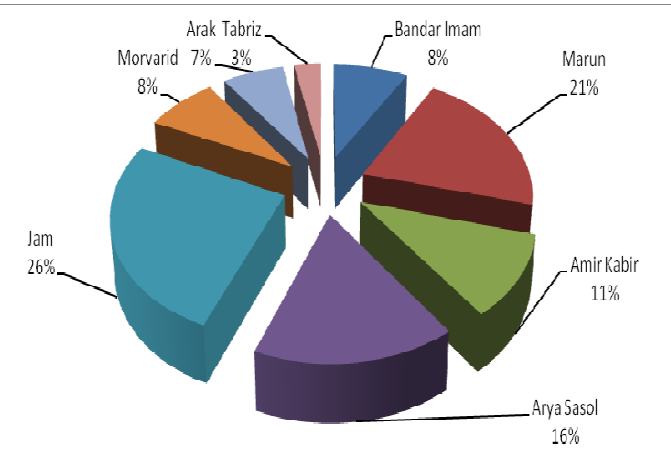

Fig1-Production capacity distribution of Iranian olefin plants in 2011 ( \% )

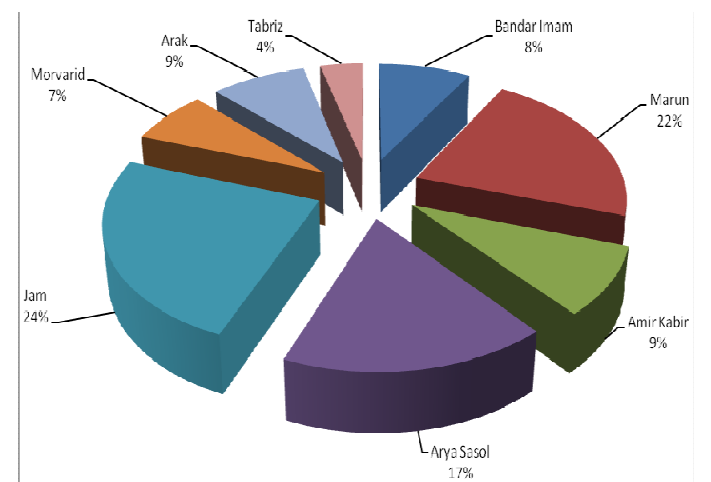

Fig2- Operational Production distribution of Iranian olefin plants in 2011 ( \% ) 


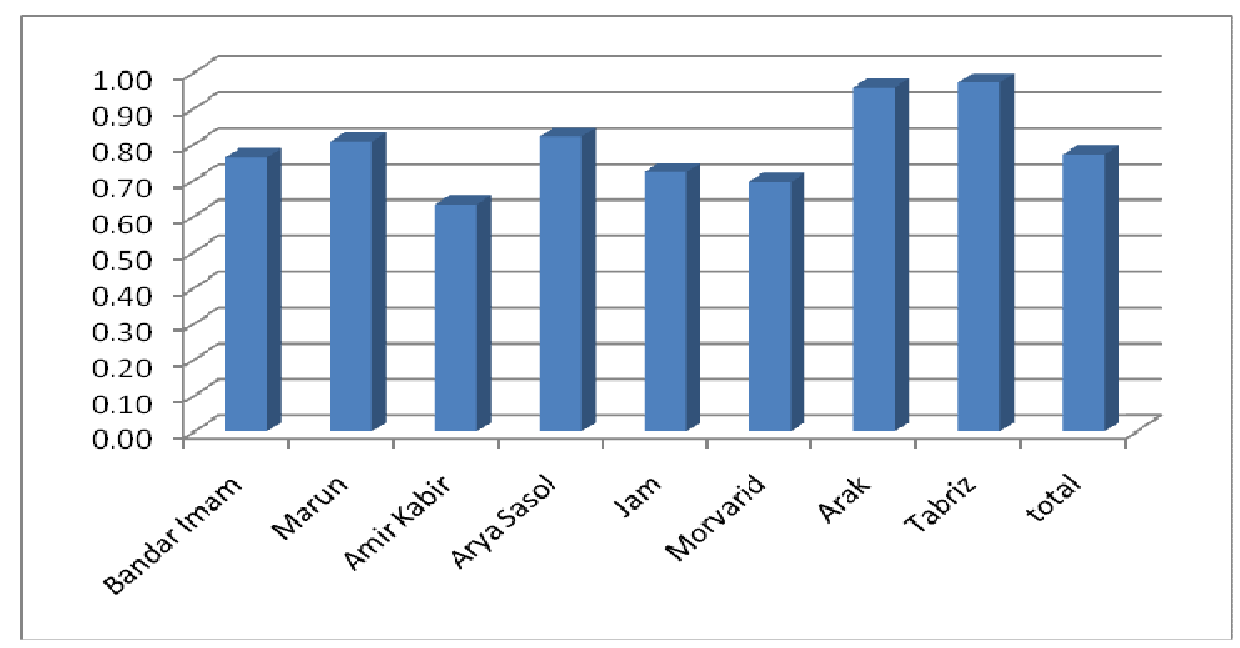

Fig3- Load factor in 2011 (ratio of actual production to design production capacity)

Tabriz and Bandar Imam are oldest production plants in Iran, so the detailed study on these sites was done. All the required data for mass \& energy balance were collected and validated with proper engineering softwares. BT index of these sites was calculated Using benchmarking and process integration tools in different sections of them. BT index shows the opportunities of energy efficiency improvement in the process.
SEC and BT index of Operating olefin plants:

The SEC of operating plants according to table-1 was calculated in design and operational conditions during one year period of time. The gap between operational and design condition was used to find non cost and low cost opportunities of improvement. The following table shows the results of the SEC calculation and no cost operational energy saving potential in each plant.

Table 2- olefin plants in Iran

\begin{tabular}{|c|c|c|c|c|c|}
\hline \multirow{2}{*}{ Row } & \multirow{2}{*}{ Plant name } & \multicolumn{2}{|c|}{ Annual HVP Production ( kTon/yr ) } & \multicolumn{2}{c|}{ Gap between operational and design } \\
\cline { 3 - 6 } & & Design & Operation & SEC ( Gj /ton) & $\begin{array}{c}\text { Equivalent Saving } \\
\text { MMNm3/yr Natural gas }\end{array}$ \\
\hline 1 & Bandar Imam & 528 & 404 & 6.7 & 72.7 \\
\hline 2 & Marun & 1300 & 1001 & 5.6 & 149.6 \\
\hline 3 & Amir Kabir & 678 & 508 & 6.1 & 82.9 \\
\hline 4 & Arya Sasol & 1000 & 774 & 0.5 & 9.4 \\
\hline 5 & Jam & 1626 & 1089 & 10.7 & 313.4 \\
\hline 6 & Morvarid & 500 & 252 & 7.4 & 49.9 \\
\hline 7 & Arak & 434 & 401 & 4.6 & 49.9 \\
\hline 8 & Tabriz & 192 & 187 & 6.4 & 32.0 \\
\hline
\end{tabular}

The detailed study was done on BIPC and Tabriz olefin plants. The following tables shows the calculation results in these plants. Bandar Imam Plant (BIPC) has a larger inefficiency gap indicating that there is a greater potential to save energy. Although it is larger than Tabriz; it is also older and was constructed at a time when many energy efficient ideas were not incorporated due to the abundance of fuel The BT index allows for direct comparison of the processes as it assesses the performance of the plants against an achievable design, with parameters accounting for variations in operation such as yield. Best technology olefins plants generate power and steam at high efficiencies and of sufficient quantity that they do not need to import either utility, however both the Bandar Imam and Tabriz plants import power and steam and this significantly contributes to their BT score. 
Table 3- SEC Calculation in BIPC and Tabriz

\begin{tabular}{|c|c|c|c|}
\hline \multicolumn{2}{|c|}{ Bandar Imam (BIPC) Olefins } & \multicolumn{2}{|c|}{ Tabriz Olefins } \\
\hline Plant Feed Rate & $108.7 \mathrm{~T} / \mathrm{hr}$ & Plant Feed Rate & $42.8 \mathrm{~T} / \mathrm{hr}$ \\
\hline Product Rate & & Product Rate & \\
\hline Ethylene & $52.7 \mathrm{~T} / \mathrm{hr}$ & Ethylene & $15.7 \mathrm{~T} / \mathrm{hr}$ \\
\hline Propylene & $16.7 \mathrm{~T} / \mathrm{hr}$ & Propylene & $6.6 \mathrm{~T} / \mathrm{hr}$ \\
\hline Total HVP & $69.4 \mathrm{~T} / \mathrm{hr}$ & Total HVP & $22.3 \mathrm{~T} / \mathrm{hr}$ \\
\hline Energy Consumption & & $\begin{array}{c}\text { Energy } \\
\text { Consumption }\end{array}$ & \\
\hline Fuel & $1113 \mathrm{Gj} / \mathrm{hr}$ & Fuel & $416 \mathrm{Gj} / \mathrm{hr}$ \\
\hline Steam & $608 \mathrm{Gj} / \mathrm{hr}$ & Steam & $73 \mathrm{Gj} / \mathrm{hr}$ \\
\hline Power & $66 \mathrm{Gj} / \mathrm{hr}$ & Power & $46 \mathrm{Gj} / \mathrm{hr}$ \\
\hline Total & $1786 \mathrm{Gj} / \mathrm{hr}$ & Total & $535 \mathrm{Gj} / \mathrm{hr}$ \\
\hline Existing SEC & & Existing SEC & \\
\hline Ethylene Based & $33.9 \mathrm{Gj} / \mathrm{Ton}$ & Ethylene Based & $34 \mathrm{Gj} / \mathrm{Ton}$ \\
\hline HV Product Based & $25.7 \mathrm{Gj} / \mathrm{ton}$ & HV Product Based & $24 \mathrm{Gj} / \mathrm{ton}$ \\
\hline
\end{tabular}

The energy allowance for Tabriz and BIPC olefin plants was calculated for different sections of each plant. It was done using process integration software and also using BT efficiencies for energy conversion systems such as power and steam generation systems, furnaces and so on. Then The BT index for Tabriz and BIPC plant was calculated for each section and also for overall plant. Table 4 shows the results of BT index gap analysis in BIPC Olefin plant.

Table 4- BIPC olefin plant inefficiency gaps

\begin{tabular}{|c|c|c|c|c|}
\hline \multirow{2}{*}{ Bandar Imam Plant(BIPC) } & Gap (GJ/h) & Energy Use (GJ/h) & BT Index (\%) & \multirow{2}{*|}{ BT Reduction (\%) } \\
\hline Current & & 1748 & 185 & \\
\hline Fired Heater Efficiency & 99 & 1649 & 174 & $\mathbf{1 0 . 5}$ \\
\hline Heat Integration Gap & 72 & 1577 & 167 & $\mathbf{7 . 7}$ \\
\hline Process Gap & 237 & 1340 & 142 & $\mathbf{4 1 . 6}$ \\
\hline Power and Shaft work Efficiency & 394 & 946 & 100 & \\
\hline 100\% BT & & 946 & 100 & \\
\hline
\end{tabular}

The Tabriz current operating BT index is actually higher than Bandar Imam's. The main reason for this is that the power imported is significantly more expensive than the fuel; therefore ideally the plant should generate as much power from fuel as possible. The key area to their position is the operation of the process furnaces. Table 5 shows the

Table 5- olefin BT Comparison

\begin{tabular}{|l|c|c|c|}
\hline \multicolumn{1}{|c|}{ Olefins } & Units & Tabriz & BIPC \\
\hline BT Score & & $218 \%$ & $185 \%$ \\
\hline Actual Energy consumption & $\mathrm{GJ} / \mathrm{h}$ & 788.4 & 1748 \\
\hline Energy Allowance & $\mathrm{GJ} / \mathrm{h}$ & 361.9 & 945.9 \\
\hline GAP & $\mathrm{GJ} / \mathrm{h}$ & 426.5 & 802.1 \\
\hline HV Products & $\mathrm{t} / \mathrm{h}$ & 22.3 & 69.4 \\
\hline
\end{tabular}

Achievable SEC for BIPC and Tabriz olefin plant was calculated. The detailed gap analysis indicates the opportunity of energy saving in different categories with different results of olefin BT score in Tabriz and BIPC. The Bandar Imam plant has the highest Energy allowance and gap. The results of detailed gap analysis for this plant are illustrated in the fig-4, which shows the largest inefficiency in Power and the shaft work.

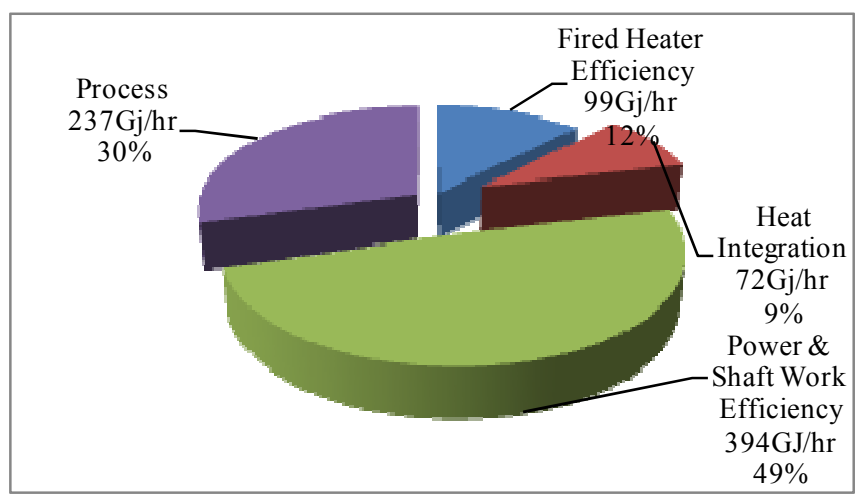

Fig4- BIPC olefin plant Energy Gap pie chart

investment and pay back periods. The reliable projects listed in the following categories according to technical and economical parameters [11]. 
- Non-investment projects, implementation and optimization (operational)

- Minor investment projects, design, implementation and optimization

- Investment projects, design, implementation and optimization (Major Investment, pay back $<5$ years)
- Investment projects, design, implementation and optimization (Major Investment, Pay back $<3$ years)

Table-6 shows current SEC in BIPC and Tabriz olefin plants and also the estimated achievable SEC related to different categories of projects mentioned above.

Table 6- current SEC in BIPC and Tabriz olefin plants

\begin{tabular}{|c|c|c|c|c|c|c|}
\hline Site & Plant & $\begin{array}{l}\text { Current } \\
\text { SEC }\end{array}$ & $\begin{array}{c}\text { Estimated } \\
\text { Achevable } \\
\text { SEC(Operational) }\end{array}$ & $\begin{array}{l}\text { Estimated } \\
\text { Achevable } \\
\text { SEC(Minor } \\
\text { Investment) }\end{array}$ & $\begin{array}{c}\text { Estimated Achevable } \\
\text { SEC(Majer Investment, } \\
\text { payback }<3 \text { years ) }\end{array}$ & $\begin{array}{c}\text { Estimated Achevable } \\
\text { SEC(Majer Investment, } \\
\text { payback }<5 \text { years ) }\end{array}$ \\
\hline & & Gj/t HVP & $\mathrm{Gj} / \mathrm{t} \mathrm{HVP}$ & $\mathrm{Gj} / \mathrm{t} \mathrm{HVP}$ & Gj/t HVP & Gj/t HVP \\
\hline BIPC & Olefins & 25.7 & 24.9 & 24.3 & 22.2 & 19.4 \\
\hline Tabriz & Olefins & 21.7 & 21.4 & 21 & 20.2 & 20.2 \\
\hline
\end{tabular}

The following assumptions have been used in this calculation:

- The meaning of import is utilities taken from outside the plant's battery limits

- The power imported has been converted to a primary energy source. The energy value of the power imported from the site has been calculated assuming that an external power station would be generating power at an efficiency of $35 \%$ equivalent to a fuel consumption of $10.3 \mathrm{GJ}$ per MWh of power.

- Steam imported has been converted to a primary energy source. The energy value of the steam imported has been calculated assuming an external generation efficiency of $92 \%$.
- Fuel consumption includes fuel imported and any off gas from the process that is routed to the furnaces for fuel. Steam internally generated and consumed has been accounted for as fuel consumed.

- Where fuel, steam or power is exported then an energy credit is applied. There is also a credit if there is a significant high temperature condensate return to outside of battery limits.

- The auxiliary utilities - cooling water, nitrogen, plant air, instrument air, potable water and fire water - have not been included in this equation as these tend to be insignificant energy consumers (in comparison to fuel, steam and power), normally in constant use and are often already included in the power import table1.

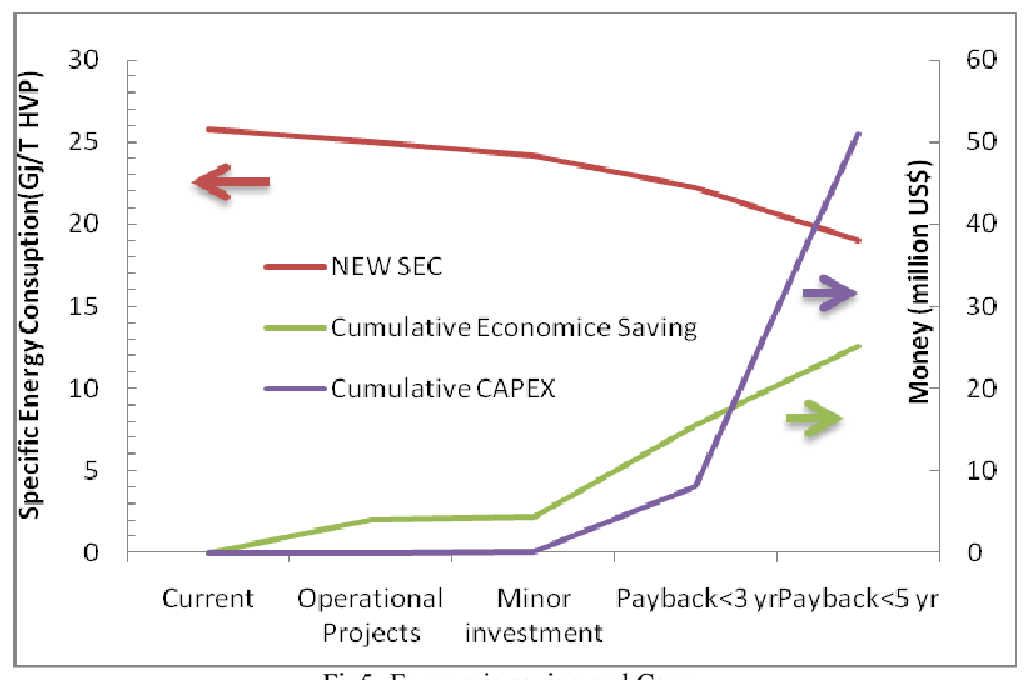

Fig5- Economic saving and Capex 


\section{Energy saving and roadmap}

The detailed study of two plants and SEC comparison on other olefin production plants illustrate high opportunity for energy saving. The total estimated energy saving for all olefin plants is about $757.9 \mathrm{MMNm}^{3} / \mathrm{yr}$ of natural gas. The roadmap to achieve the estimated energy saving in BIPC is shown in fig 5. The SEC, economic saving and Capex cost of BIPC olefin plant versus payback period is illustrated in fig -5 .

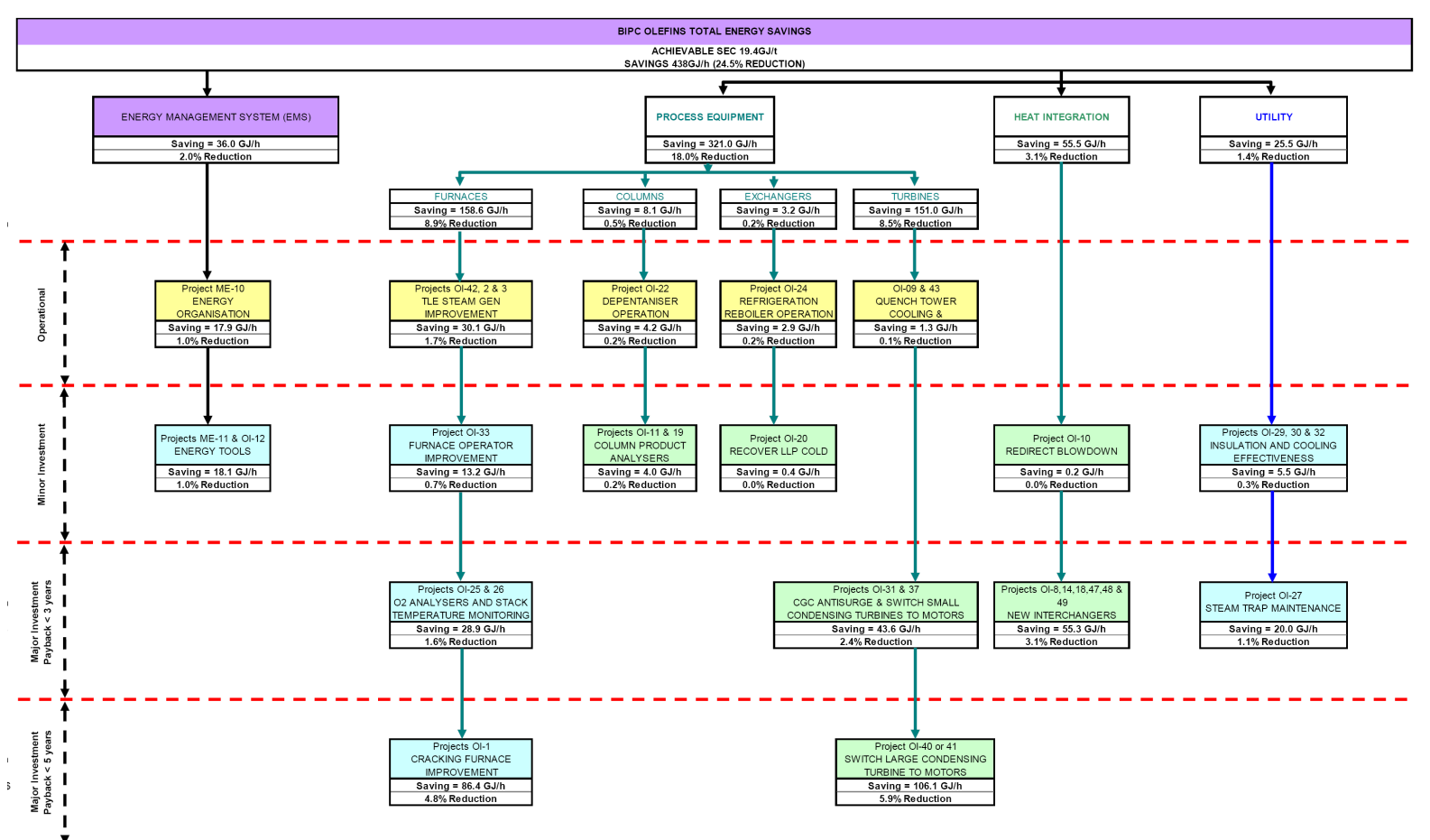

Fig6- roadmap BIPC olefin plant

\section{Conclusion}

Olefin plants are one of the most energy intensive production plants of chemical and petrochemical industries which use hydrocarbons as fuel and feed. This paper shows the existing situation of olefin production plants in Iran and also the energy saving opportunities in these sites. The SEC for new olefin plants was offered and approved by IFCO (Iranian Fuel Conservation Company) as $20 \mathrm{Gj}$ /Ton of HVP in olefin plants. The economically attractive improvement opportunities have been identified within the 2 detailed studied plants. It is estimated that total implementation of these projects will save over $102 \mathrm{Nm} 3 / \mathrm{yr}$ of equivalent natural gas in energy use. On the other hand there is a potential of energy reduction more around 656 Million $\mathrm{NM}^{3} / \mathrm{yr}$ in other olefin production plants which corresponds to 1.36 Million Ton of $\mathrm{CO}_{2}$ Reduction in Iranian olefin plants.

\section{Acknowledgement}

The authors would like to thank Iranian Fuel Conservation Company (IFCO) for supporting the bulk of this work and project.

\section{References}

[1] IEA, Tracking Industrial Energy Efficiency and $\mathrm{CO} 2$ Emissions OECD/IEA, 2007

[2] Tao Ren, Martin Patel, Kornelis Blok, Olefins from conventional and heavy feedstocks: Energy use in steam cracking and alternative processes, Energy, Volume 31, Issue 4, 2006, pp 425-451.

[3] Deger Saygın, Martin K. Patel,Ceci lia Tam, Dolf J. Gielen ,IEA, Chemical and Petrochemical Sector Potential of best practice technology and other measures for improving energy efficiency.2009 
[4] Tao Ren, Martin K. Patel, Kornelis Blok, Steam cracking and methane to olefins: Energy use, $\mathrm{CO}_{2}$ emissions and production costs Energy Volume 33, Issue 5, May 2008, Pages $817-833$

[5] J. d. Beer, "Potential for industrial energy efficiency improvement in the long term," P. D. W. C. Turkenburg and D. K. Blok, Eds.: Utrecht, 1998, pp. 278.

[6] L. F. Albright, B. L. Crynes, and S. Nowak, "Novel production methods for Ethylene, light hydrocarbons and aromatics," New York: Marcle Dekker Inc., 1992.

[7] Hydrocarbon-Processing, "Petrochemical Processes," Hydrocarbon Processing, March 2003

[8] ChemSystems, "Process Evaluation/Research Planning: PERP 2002/2003 Program (Appendix II Production Cost Tables)," Chem System/Nexant Inc., 2002

[9] Douglas C White, Emerson Process Management, "OLEFIN PLANT ENERGY SAVINGS THROUGH ENHANCED AUTOMATION", AIChE Paper Number $110 \mathrm{f}$.
[10] Solomon, "Worldwide Olefins Plant Performance Analysis 1995, quoted in "Energy efficiency improvement in ethylene and other petrochemical production" By D. Phylipsen, et. al., report NW\&S 99085, Dep. of Science, Technology and Society at the Utrecht University, 1999," Solomon Associates Ltd., Windsor 1995.

Ministry of the Environment," AUTHORITIES ROLE IN THE ASSESSMENT OF ENERGY EFFICIENCY ".

[11] Marianne Lindström, Mikko Attila, Jaana Pennanen, Finnish Environment Institute Elise Sahivirta, Finnish

\section{Creative Commons Attribution License 4.0} (Attribution 4.0 International, CC BY 4.0)

This article is published under the terms of the Creative Commons Attribution License 4.0 https://creativecommons.org/licenses/by/4.0/deed.en US 